\title{
Predicting Financial Distress among SMEs in Malaysia
}

\author{
Muhammad M. Ma'aji \\ Nur Adiana Hiau Abdullah \\ Karren Lee-Hwei Khaw \\ School of Economics, Finance and Banking \\ College of Business (COB), Universiti Utara Malaysia
}

Doi: 10.19044/esj.2018.v14n7p91 URL:http://dx.doi.org/10.19044/esj.2018.v14n7p91

\begin{abstract}
Predicting financial distress among Small and Medium Enterprises (SMEs) can have a significant impact on the economy as it serves as an effective early warning signal. The study develops distress prediction models combining financial, non-financial and governance variables which were used to analyze the influence of major corporate governance characteristics, like ownership and board structures, on the likelihood of financial distress. Multiple Discriminant Analysis (MDA) model as one of the extensively documented approaches was used. The final sample for the estimation model consists of 172 companies with 50 percent non-failed cases and 50 percent failed cases for the period between 2000 to 2012. The prediction models perform relatively well especially in the model that incorporate governance, financial and non-financial variables, with an overall accuracy rate of 90.7 percent in the estimated sample. The accuracy rate in the holdout sample was 91.2 percent. This evidence shows that the models serve as efficient early warning signals and can thus be beneficial for monitoring and evaluation. Controlling shareholder, number of directors, and gender of managing director are found to be significant predictors of financially distressed SMEs.
\end{abstract}

Keywords: Financial distress, corporate governance, MDA model, SMEs, Malaysia

\section{Introduction}

The consequences of financial distress have a far-reaching impact on stakeholders either directly or indirectly. However, the major stakeholders in a company who are the shareholders stand to lose most of their investment. Creditors may receive partial or no repayment of their initial loans depending on whether their loans were secured or unsecured, employees will lose their 
jobs, the government is likely to collect less company and personnel taxes, and social problem might increase. The contributions of Altman (1968); Altman, Edward, Haldeman, and Narayanan (1977); Beaver (1966); Deakin (1977); Blum (1974); and Ohlson (1983) among others have spawned huge literature on the topic of financial distress. Since then, a number of models have been proposed in order to correctly predict corporate failure. Nevertheless, this can be seen mostly in large public listed firms due to easy access to their financial data. However, very little number of researches on small and medium enterprises (SMEs) has been done as a result of the difficulty in accessing their financial data and other information.

In recent years, SMEs are viewed to be the leading contributor to the national economic development in terms of developing entrepreneurship using indigenous skills and technologies, creating employment opportunities, building market competitiveness through innovativeness, and allowing the government to realize a poverty free society (Jahur \& Quadir, 2012). Small business in Malaysia plays a significant role towards economic development in the country. Therefore, understanding why SMEs businesses fail is vital to the stability and health of the Malaysian economy. Most of the research contributions done in Malaysia regarding corporate failures have been focusing on public listed entities due to easy access to financial data using many bankruptcy prediction models such as univariate analysis, logit regression model, multiple discriminant analysis (MDA), hazard model, and probit model (Abdullah, Halim, Ahmad \& MD. Rus, 2008; Halim, Mohd, Rizal \& Marzuki, 2008; Md-Rus, Nisham, Abdul Latif, \& Nadakkavil, 2013; Norfian, 2013; Sulaiman, 2001; Zulkarnian, 2006; Zulkarnian, Ali, Md. Nasir, \& Mohamad, 2001; and Zulridah, 2012). Referring to the aforementioned limitations, the study aims to explore the manufacturing sector of Malaysian SMEs in order to predict financial distress as early as two years. This is done using financial, non-financial, and corporate governance information and is, therefore, used for examining the accuracy rate of the model.

The remaining part of our paper proceeds as follows. In section 2, an overview of the extant literature on failure prediction is included. In section 3 , we provided an analysis of the Malaysia sample used in the study. In section 4, financial distress model for SMEs is presented to test the impact of adding governance variables to predict financial distress. Finally, section 5 provides a concluding discussion.

\section{Literature Review}

Edminister (1972) was among the early research on SMEs business failure. Thus, it also employs MDA statistical technique to discriminate among loss and non-loss SME borrowers. His analysis resulted in MDA model with seven financial ratio variables. Classification accuracy of the model was 93 
percent, while the model error was 7 percent. Therefore, the research reveals that classifying ratios by quartile is a particularly valuable tool. Consequently, this can be demonstrated by the use of quartiles in every variable of the study. This is because extreme values are negated and are therefore prevented from unduly affecting the function parameters (Edminister, 1972). Lugovskaja (2009) uses MDA model in his paper to predict bankruptcy among Russian SMEs. The research sample consisted of 260 bankrupts and 260 randomly chosen healthy SMEs. The author developed two models; model one considering financial variables while model two include both financial and non-financial variables. The first MDA model resulted with the finding that the following six variables were significant for bankruptcy prediction: current liabilities/total assets, cash/current liabilities, ROA and cash/ total assets, current assets/current liabilities, and cash plus short-term debtors/current liabilities. The second MDA model besides financial ratios included nonfinancial variables (size and age), which both appears to be significant. The classification accuracy for the model with just financial ratios was 76.2 percent, while it was 68.1 percent for holdout sample. Model with financial ratios and non-financial variables had higher classification accuracy (77.9 percent for estimation sample and 79 percent for holdout sample).

Sirirattanaphonkun and Pattarathammas (2012) used bank data in order to predict failure as banks required SMEs to submit their financial data as part of a loan agreement. Data were also derived from the private and public authority of Thailand such as BOL database. Thus, their study used many financial ratios to predict failure. Variables such as liquidity ratio, profitability ratio, and leverage ratios appeared to be statistically significant. The result shows that the Logit model gives higher predictive accuracy at 85.5 percent for the out-of-sample test. Furthermore, the pooled estimation of bankruptcy firms from both MDA and Logit models could help achieve even higher predictive accuracy level. Abdullah et al. (2014) in their contribution studied 132 privately-owned SMEs in the manufacturing sector in Malaysia during the period 2000-2010. Their empirical result shows that higher gearing and lower profitability entailed a higher probability of failure and when firm age is added to the model as a non-financial variable, they found it to be significant resulting to an increase in the model's classification accuracy. Receiver Operating Characteristics (ROC) curve demonstrates that both models possess better predictive ability than a random model. Consequently, model two which includes financial and non-financial variables show superior performance. The accuracy rate that the model could correctly predict failures ranges from 75 to 89 percent and the model could be used as a refined tool to avoid possible adverse situations among the SMEs. 


\section{Methodology}

Companies Commission of Malaysia (CCM) database (an autonomous body that functions as a one-stop center for corporate information, regulation and development of conducive business environment) was used in this study to identify the sample which consists of both distressed and non-distressed SMEs for a twelve-year observation period from 2000 to 2012. Companies were matched based on the same industry group and close in asset size, i.e. failed companies were matched against healthy companies that have an almost similar total asset. Financial statements are used to extract the financial variables and the companies profile was used to obtain the non-financial and corporate governance variables. As mentioned earlier, the study focused on companies in the manufacturing sector as the sector contributes significantly to the economic development of Malaysia.

The final sample for the estimation model consists of 172 companies (50 percent non-failed cases and 50 percent failed cases). Twenty percent of the estimated sample was retained as a test sample (hold-out sample). The companies were selected based on the SME's definition adopted by the National SME Development Council as discussed earlier. Also, that company is classified under winding off by court order or creditors request in Part X Section 218 of 1 (e) and (2) of Malaysian Companies Act 1965. Data for two years prior to failures were used in the estimation analysis because most of the failed companies did not submit their financial reports when the winding-up period approached. Hence, this has led to a very small sample for the year prior to failure.

To investigate whether governance variables influence the occurrence of distress, an MDA model function of the following form was estimated:

$D=\alpha+\beta_{1} C O N T+\beta_{2} F R G N+\beta_{3} N D I R+\beta_{4} G E N D E R+\beta_{5} T L A+$ $\beta_{6} S L A+\beta_{7} L Q T+\beta_{8} S T A+\beta_{9} E B I T+\beta_{10} N I S+\beta_{11} \log T A+\beta_{12} \log C A P$ $+\beta_{13} A G E$

Where D refers to discriminant score, $\alpha$ refers to estimated constant, CONT is a dummy for controlling shareholder that is equal to 1 otherwise zero, FRGN is a dummy for foreign ownership that is equal to 1 otherwise zero, NDIR is number of directors on the board, GENDER is a dummy for gender of managing director that equal to 1 otherwise zero, TLA is ratio of total liabilities to total assets, SLA is ratio short term liabilities to total assets, LQT is ratio of current assets to current liabilities, STA is ratio of sales to total asset, EBIT is ratio of earnings before interest and tax to total asset, NIS is ratio of net income to share capital, LogTA is logarithm of total assets, LogCAP is logarithm of share capital, and AGE is years of firm business operations.

A forward stepwise procedure was applied which allowed the predictor variables to be included only based on the contribution they made. A stepwise procedure is usually applied when there is lack of theoretical basis in the 
selection of the predictor variables (Low, Fauzias, \& Zainal Ariffin, 2001). Basically, there are three (3) models that have been developed. They are Model 1 (include financial and non-financial variables only); Model 2 (include governance variables only) and Model 3 (include financial, non-financial and governance variables).

Model 1 utilizing only financial and non-financial variables as used by Abdullah et al. (2014) is to act as a benchmark which is used to compare the results obtained by model 2 and 3. Model 2 would only include the governance variables, whereas model 3 aims to incorporate both financial, non-financial, and governance variables that is designed to test whether the three set of information in conjunctions is able to produce a superior result to those obtained from either model 1 or model 2.

\section{Findings and Discussion Descriptive Statistics}

Table 1 presented the results of mean differences on the variables used to estimate the MDA model. Overall, out of the thirteen independent variables, foreign owners, liquidity, and the logarithm of the total asset are not significantly different between distressed and non-distressed SMEs. The result indicated that 92 percent of distressed SMEs are holding 25 percent or more of the voting right, whereas only 30 percent of the non-distressed SMEs are holding 25 percent or more of the voting right. On average, there is only 29 percent and 23 percent of distressed and non-distressed SMEs which are having foreign ownership. It appears that 94 percent of the distressed SMEs are having a male Managing Director (MD), while there is only 52 percent of the non-distressed SMEs that are having a male MD. For non-distressed SMEs, the average board size is four directors, while for distressed SMEs, the average board size is only two directors.

Table 1. Descriptive Statistics

\begin{tabular}{cccccc}
\hline Variables & Mean & $\begin{array}{c}\text { Panel Pool (2 years prior) } \\
\text { Standard } \\
\text { Deviation }\end{array}$ & Mean & $\begin{array}{c}\text { Standard } \\
\text { Deviation }\end{array}$ & Sig \\
& \multicolumn{2}{c}{ Distressed SMEs } & Non-distressed SMEs & \\
\hline FRGN & 0.290 & 0.457 & 0.230 & 0.425 & 0.389 \\
CONT & 0.920 & 0.275 & 0.30 & 0.439 & $0.000^{* * *}$ \\
NDIR & 2.26 & 0.490 & 3.56 & 1.523 & $0.000^{* * *}$ \\
GENDER & 0.940 & 0.235 & 0.520 & 0.504 & $0.000^{* * *}$ \\
TLA & 1.639665 & 1.6988932 & 1.069736 & 1.7074397 & $0.000^{* * *}$ \\
SLA & 0.932847 & 0.1297635 & 0.867709 & 0.1846139 & $0.008^{* * *}$ \\
LQT & 1.5833955 & 5.4147794 & 2.103312 & 4.1362782 & 0.481 \\
STA & 1.238576 & 1.3326733 & 0.946171 & 0.7062023 & $0.074 *$ \\
EBIT & -0.269019 & 0.5949879 & 0.023244 & 0.1410697 & $0.000^{* * *}$ \\
NIS & -0.795062 & 1.9086819 & 0.089221 & 2.1888388 & $0.005^{* * *}$ \\
LogTA & 15.495015 & 1.4151391 & 15.566687 & 1.4984732 & 0.747 \\
LogCAP & 14.266799 & 1.4777394 & 13.715486 & 1.5857497 & $0.000^{* * *}$ \\
AGE & 14.87 & 7.162 & 20.26 & 5.537 & $0.000^{* *}$
\end{tabular}


Observation

86

86

$*, * *, * * *$ significant at 10 percent, 5 percent and 1 percent levels respectively. Foreign owner (FRGN), sex of MD (GENDER), controlling shareholder (CONT), number of directors (NDIR), age of company (AGE), logarithm of total assets (LogTA), logarithm of share capital (LogCAP), total liabilities to total assets (TLA), short term liabilities to total assets (SLA), liquidity (LQT), sales to total assets ( STA), earnings before interest and tax to total assets (EBIT), net income to share capital (NIS). Observation is the number of companies in the analysis.

Keasey and Watson (1987) highlighted some benefits for SMEs in having a large number of directors in the board among which he argued it will increase the efficiency of the board. This is because directors will have better chances of communicating, listening to each other, and keeping the discussions on track. He also argued that the individual board members will add value to the business and supply any necessary skills in the areas of strategy and/or management and operations' oversight.

Furthermore, in consistency with the previous researches, distressed SMEs are having a high level of debt liabilities and lower liquidity which resulted in negative basic earnings power and net income to share capital. However, both groups are considered to be relying heavily on short-term liabilities to finance their day-to-day business operations. Smaller companies often rely heavily on trade finance from suppliers when bank finance is not available to them (Altman et al., 2010). The average age of distressed SMEs is 15 years, whereas non-distressed SMEs have been in operations for about 20 years. There are little differences in terms of asset for distressed and nondistressed SMEs as the companies match together based on assets.

Multicollinearity is not a threat to this study as indicated by a variance inflating factor (VIF) reported in Table 2 . The $\mathrm{R} 2$ are relatively low for all the variables. The VIF ranges from 1.170 to 1.640 which is less than 10 , indicating that there is no issue of multicollinearity to this study.

Table 2. Variance inflating factor

\begin{tabular}{ccc}
\hline Variables & $\mathrm{R}^{2}$ & $\mathrm{VIF}=1 /\left(1-\mathrm{R}^{2}{ }_{\mathrm{j}}\right.$ \\
\hline FRGN & 0.145550 & 1.170 \\
GENDER & 0.316608 & 1.463 \\
CONT & 0.310184 & 1.449 \\
NDIR & 0.259417 & 1.350 \\
Age & 0.216671 & 1.277 \\
LogTA & 0.390370 & 1.640 \\
logCAP & 0.270086 & 1.370 \\
TLA & 0.348245 & 1.534 \\
STD & 0.200863 & 1.251 \\
LQT & 0.155651 & 1.184 \\
STA & 0.243614 & 1.322 \\
EBIT & 0.359935 & 1.562 \\
NIS & 0.198037 & 1.247 \\
\hline
\end{tabular}

Foreign owner (FRGN), sex of MD (GENDER), controlling shareholder (CONT), number of directors (NDIR), age of company (AGE), logarithm of total assets (LogTA), logarithm of 
share capital (LogCAP), total liabilities to total assets (TLA), short term liabilities to total assets (SLA), liquidity (LQT), sales to total assets ( STA), earnings before interest and tax to total assets (EBIT), net income to share capital (NIS).

\section{Multiple Discriminant Analysis}

Using a sample of matched distressed and non-distressed SMEs as dependent variables together with financial, non-financial and governance factors as independent variables, a stepwise discriminant analysis is used to ascertain the discriminating power of the variables. Stepwise MDA allows the variables selected for analysis to be ranked according to their influence on the final result. The variable with the highest influence that passes the test of eligibility is then included in the examination. At each stage, the variables that has been selected already were also tested against an exclusion criterion and they may be excluded from the analysis if they fail to satisfy the condition. The process continues until there are no variables that can be entered or removed from the analysis (Pattarathammas, 2012).

Table 3. Stepwise MDA analysis for estimated models

\begin{tabular}{|c|c|c|c|c|c|c|c|}
\hline \multirow[b]{2}{*}{ Variables } & \multirow[b]{2}{*}{ Category } & \multicolumn{2}{|c|}{ Model 1} & \multicolumn{2}{|c|}{ Model 2} & \multicolumn{2}{|c|}{ Model 3} \\
\hline & & $\begin{array}{l}\text { Standardized } \\
\text { canonical } \\
\text { discriminant } \\
\text { function } \\
\text { coefficient }\end{array}$ & $\begin{array}{l}\text { Wilks' } \\
\text { Lambda }\end{array}$ & $\begin{array}{l}\text { Standardized } \\
\text { canonical } \\
\text { discriminant } \\
\text { function } \\
\text { coefficient }\end{array}$ & $\begin{array}{l}\text { Wilks' } \\
\text { Lambda }\end{array}$ & $\begin{array}{l}\text { Standardized } \\
\text { canonical } \\
\text { discriminant } \\
\text { function } \\
\text { coefficient }\end{array}$ & $\begin{array}{c}\text { Wilks' } \\
\text { Lambda }\end{array}$ \\
\hline FRGN & Governance & & & 0.295 & $\begin{array}{c}0.407 \\
(0.389)\end{array}$ & 0.206 & $\begin{array}{c}0.346 \\
(0.000)^{* * *}\end{array}$ \\
\hline CONT & Governance & & & 0.739 & $\begin{array}{c}0.547 \\
(0.000)^{* * *}\end{array}$ & 0.638 & $\begin{array}{c}0.547 \\
(0.000)^{* * *}\end{array}$ \\
\hline NDIR & Governance & & & -0.539 & $\begin{array}{c}0.461 \\
(0.000)^{* * *}\end{array}$ & -0.524 & $\begin{array}{c}0.461 \\
(0.000)^{* * *}\end{array}$ \\
\hline GENDER & Governance & & & 0.377 & $\begin{array}{c}0.428 \\
(0.000)^{* * *}\end{array}$ & 0.260 & $\begin{array}{c}0.385 \\
(0.000)^{* * *}\end{array}$ \\
\hline TLA & Financial & -0.261 & $\begin{array}{c}0.638 \\
(0.000)^{* * *}\end{array}$ & & & & \\
\hline EBIT & Financial & 0.484 & $\begin{array}{c}0.653 \\
(0.000)^{* * *}\end{array}$ & & & -0.233 & $\begin{array}{c}0.355 \\
(0.000)^{* * *}\end{array}$ \\
\hline LogCAP & Financial & -0.613 & $\begin{array}{c}0.731 \\
(0.000)^{* * *}\end{array}$ & & & 0.402 & $\begin{array}{c}0.405 \\
(0.003)^{* * * *}\end{array}$ \\
\hline AGE & $\begin{array}{c}\text { Non- } \\
\text { financial }\end{array}$ & 0.740 & $\begin{array}{c}0.848 \\
(0.000)^{* * *}\end{array}$ & & & -0.255 & $\begin{array}{c}0.369 \\
(0.000)^{* * * *}\end{array}$ \\
\hline Constant & & -8.884 & & -0.678 & & -3.122 & \\
\hline Wilks' & & 0.638 & & 0.407 & & 0.346 & \\
\hline Lambda & & $(0.000)$ & & $(0.000)$ & & (0.000) & \\
\hline Observation & & 138 & & 138 & & 138 & \\
\hline
\end{tabular}

$*, * *, * * *$ significant at 10 percent, 5 percent and 1 percent levels respectively. Model 1: financial and non-financial variables, model 2: governance variables, model 3: combined model 1 and 2. Foreign owner (FRGN), sex of MD (GENDER), controlling shareholder (CONT), number of directors (NDIR), age of company (AGE), logarithm of share capital (LogCAP), total liabilities to total assets (TLA), earnings before interest and tax to total assets (EBIT).

Based on the stepwise procedure, it appears that model 3 outperformed models 1 and 2 based on Wilks' lambda and classification accuracy. Wilks' 
lambda indicates the significance of the discriminant function. The smaller the Wilks' lambda for an independent variable, the more likely that the variable adds to the discriminant function. Wilks' lambda is used in the second context of discriminant analysis to test the significance of the discriminant function as a whole (Huberty, 1994). Table 3 shows that model 3 has 34.6 percent unexplained variation in the group variables, while model 1 and model 2 have 63.8 and 40.7 percent respectively. Therefore, the discriminate function in model 3 revealed a significant association between groups and all predictors, accounting for 65.4 percent of between-group variability as compared to model 1 and model 2 accounting for just 36.2 and 59.3 percent respectively.

A closer analysis of the standardized canonical discriminant function coefficient in model 3, which combined financial, non-financial and governance variables and has the lowest Wilks' lambda, revealed three significant predictors that have the highest discriminating power, namely CONT (0.638), NDIR (-0.524) and LogCAP (0.402) with FRGN (0.206), GENDER (0.260), EBIT (-0.255) and AGE (0.233) as having less discriminating power but is statistically significant. Altman (1968) also found that EBIT is among the five financial ratios that successfully discriminate between the distressed and non-distressed SMEs. Chancharat (2011) and Khunthong (1997) found a similar result with that of Altman (1968). Lugovskaja (2009) in his second MDA model that combined financial and non-financial variables found that size and age of firm appeared to have high predictive power to discriminate between distressed and non-distressed SMEs in Russia which is consistent with this study. However, model 3 stepwise procedure excludes total debt ratio among the variables that have significant influence to the group. Nevertheless, model 1 reported total debt ratio to have a high discriminating power to predict failure among SMEs.

This is consistent with the previous work of Buggakupta (2004), Kiatkhajornvoung (2008), and Sirirattanaphonkun and Pattarathammas (2012) where they found that total debt ratio is having a high predictive power to discriminate between distressed and non-distressed SMEs. The result of this study shows that if an analysis is done based on financial and non-financial variables, total debt ratio becomes significant. However, when governance variables were included, this variable becomes insignificant in discriminating the group.

Table 4. Classification accuracy rate under MDA model

\begin{tabular}{ccccccc}
\hline & \multicolumn{2}{c}{ Estimated (138 SMEs) } & \multicolumn{3}{c}{ Holdout (34 SMEs) } \\
& Distressed & $\begin{array}{c}\text { Non- } \\
\text { distressed }\end{array}$ & Overall & Distressed & $\begin{array}{c}\text { Non- } \\
\text { distressed }\end{array}$ & Overall \\
\hline Model 1 & $73.3 \%$ & $83.7 \%$ & $\mathbf{7 8 . 5 \%}$ & $64.7 \%$ & $76.5 \%$ & $\mathbf{7 0 . 6 \%}$ \\
Model 2 & $91.9 \%$ & $83.7 \%$ & $\mathbf{8 7 . 8 \%}$ & $94.1 \%$ & $82.4 \%$ & $\mathbf{8 8 . 2 \%}$ \\
Model 3 & $95.3 \%$ & $86.0 \%$ & $\mathbf{9 0 . 7 \%}$ & $100 \%$ & $82.4 \%$ & $\mathbf{9 1 . 2 \%}$ \\
Observation & & & $\mathbf{1 3 8}$ & & & $\mathbf{3 4}$ \\
\hline
\end{tabular}


Note: Model 1: financial and non-financial variables, model 2: governance variables, model 3: combined model 1 and 2. Observation is number of companies in the analysis.

To validate the model's accuracy, the cross-validated classification showed that overall model 3 is having the highest predictive accuracy both in the estimated and holdout samples. Overall, 90.7 and 91.2 percent were correctly classified in the estimated and holdout sample respectively. Model 3 outperformed model 1 that is used as a benchmark to compare the results from the other models. The results clearly suggest that the model which incorporates financial, non-financial, and governance variables will have a better predictive accuracy. This is in contrast with Lugovskaja (2009) who suggests that a model with financial and non-financial variables had higher classification accuracy both in the estimated and holdout samples.

\section{Conclusion}

The study builds on the previous work of Abdullah et al. (2014) that utilized financial and non-financial variables in predicting failure among SMEs in Malaysian manufacturing sector. In this study, governance variables are included to see whether or not by having financial, non-financial and governance variables, it is possible to achieve higher prediction accuracy rate of SMEs failure.

The study improves upon the existing models from the literature of SME distressed prediction in various ways. In addition, the study presented new empirical findings on predicting financially distressed SMEs in the manufacturing sector for the period between 2000 to 2012. It also explores the value added of governance variables to the prediction model and where the prediction accuracy improves significantly to 90.7 percent against 81.2 percent of the logit model in Abdullah et al. (2014). This, however, utilized only financial and non-financial information. Generally, the governance variables examined in this study were chosen to capture some important SME's characteristics.

The findings clearly confirm what has been found in other studies for large corporations, that using governance variables as predictors of company failure significantly improves the prediction model's accuracy rate (Lackshan \& Wijekoon, 2012; Md-Rus et al., 2013; Polsiri \& Kingkan, 2009). The results showed that most of the distressed SMEs are having a large number of controlling shareholders. Non-distressed SMEs are having more directors in their board which may help to increase oversight, monitoring, and expertise in the company's operations. As a result, distressed SMEs are having less number of directors which increase the likelihood of failure among SMEs. The male managing director is also positively related to failure. However, foreign ownership appears to be unrelated to the failure status. Young SMEs seems to be more likely to fail compared to longer existence of SMEs due to experience 
and growth development. In addition, the debt ratio is positively related to failure among SMEs. The findings affirm that small business in Malaysia finance most of their business operation using bank loan as they have limited access to capital market. The result also shows that EBIT is negatively related to failure and distressed SMEs are less profitable compared to non-distressed SMEs as a result of huge amount of liabilities that trim their profit.

However, a number of shortcomings of MDA have been pointed out by Ohlson (1980) when applied to failure prediction problems. In MDA, the standardized coefficients cannot be interpreted like the slopes of a regression equation. Ohlson also notes that the requirement that the predictor variables should be normally distributed clearly is not fulfilled by the use of governance data (mostly dummy variables). One of the assumptions underlying the efficient use of discriminant analysis is that the variables are multivariate normal in their distribution. Therefore, this condition is not fulfilled by the non-financial and governance data.

\section{References:}

1. Abdullah, N., Ahmad, A., Ahmad, H \& Md. Rus, R. (2008). "Predicting corporate failure of Malaysia's listed companies: Comparing multiple discriminant analysis, logistic regression and the hazard model", International Research Journal of Finance \& Economics, Vol. 15, pp. 201-217.

2. Abdullah, N., Ahmad, A., Md. Rus, R., \& Zainuldin, N. (2014). "Modelling small business failures in Malaysia", available at: http://ssrn.com/abstract =2402129

or http://dx.doi.org/10.2139/ssrn.2402129

3. Altman, E. (1968). "Financial ratios, Discriminant Analysis and the Prediction of Corporate Bankruptcy", Journal of Finance, Vol. 23, pp. 589-609.

4. Altman, E., Edward, I., Haldeman, R., \& Narayanan, P. (1977). “A new model to identify bankruptcy risk of corporation". Journal of Banking and Finance, Vol. 1, pp. 29-54.

5. Altman, E., Sabato, G., \& Wilson, N. (2010). "The value of nonfinancial information in small and medium- sized enterprise risk management". Journal of Credit Risk, Vol. 6, N0. 2, pp. 95-127.

6. Beaver, W. (1967). "Financial ratios as predictor of failure", Journal of Accounting Research, Vol. 4, pp. 71- 111.

7. Blum, M. (1974). "Failing company discriminant analysis". Journal of Accounting Research, Vol. 12, N0. 1, pp. 1-25.

8. Buggakupta, S. (2004). "The development of a Thai da model and its comparison with Altman's (1993) model in predicting failure of Thai listed companies", Doctoral Dissertation, Ramkhamhaeng University. 
9. Chancharat, N. (2011). "SMEs failure prediction: Literature review", ABAC Journal, Vol. 31, N0. 3, pp. 7081.

10. Deakin, E. (1972). "A discriminant analysis of predictors of business failure", Journal of Accounting Research, Vol. 10, N0. 1, pp. 167-179.

11. Edminster, R. (1972). "An empirical test of financial ratio analysis for small business failure prediction", Journal of Financial and Quantitative Analysis, pp. 1477-1493.

12. Huberty, J. (1994). "Applied Discriminant Analysis", available at: Wiley Series in Probability and Statistics, 297.

13. Jahur, M., \& Quadar, S. (2012). "Financial distress in small and medium enterprises (SMEs) of Bangladesh: Determinants and remedial measures". Economia Series Management, Vol. 15, N0. 1, pp. 432-444.

14. Keasey, K., \& Watson, R. (1987). "Non-financial symptoms and the prediction of small company failure: a test of Argenti's hypotheses", Journal of Business Finance and Accounting, Vol. 14, N0. 3, pp. 335354.

15. Kiatkhajornvong, N. (2008). "Credit risk model for listed companies in Thailand", Dissertation, Thammasat University.

16. Low, S., Fauzias, M., \& Zainal Ariffin, A. (2001). "Predicting corporate distress using logit model: The case of Malaysia", Asian Academy of Management Journal, Vol. 6, N0. 1, pp. 49-62.

17. Lugovskaja, L. (2009). "Predicting default of Russian SMEs on the basis of financial and non-financial variables", Journal of Financial Services Marketing, Vol. 14, N0. 4, pp. 301-313.

18. Md-Rus, R., Nisham K., Abdul Latif, R., \& Nadakkavil, Z. (2013). "Ownership Structure and Financial Distressed", Journal of Advanced Management Science, Vol. 1, N0. 4, pp. 363-267.

19. Norfian, M. (2013). "Prediction of financial distress companies in Malaysia: a comparison between consumer products and industrial products sectors", 2nd International Conference on Management, Economics and Finance (2nd ICMEF 2013) Proceeding, ISBN: 978967-5705-12-0, 382-392.

20. NSDC (2013). "Guidelines for New SME Definition, SME Corp. Malaysia", retrieved from http://www.smecorp.gov.my/vn2/node/533

21. Ohlson, J. (1980). "Financial ratios and the probabilistic prediction of bankruptcy", Journal of Accounting Research, Vol. 18, 109-131.

22. Sirirattanaphonkun, S. \& Pattarathammas, M. (2012). "Default prediction for small-medium enterprises in emerging market: Evidence from Thailand", Seoul Journal of Business, Vol. 18, N0. 2, pp. 25-54. 
23. Zulkarnian, M., Ali, M., Md. Nasir, A., \& Mohamad, Z. (2001). "Forecasting corporate failure in Malaysian industrial sector firms", Asian Academy of Management Journals, Vol. 6, N0. 1, pp. 15-30.

24. Zulkarnian, M. (2006). "Prediction of corporate financial distress: evidence from Malaysian listed firms during the Asian financial crisis", Staff paper 2/2006, University Putra Malaysia.

25. Zulridah, M. (2012). "Corporate governance and corporate failure: A survival analysis”, Prosiding Perkem, Vol. 7, N0. 1, pp. $684-695$. 